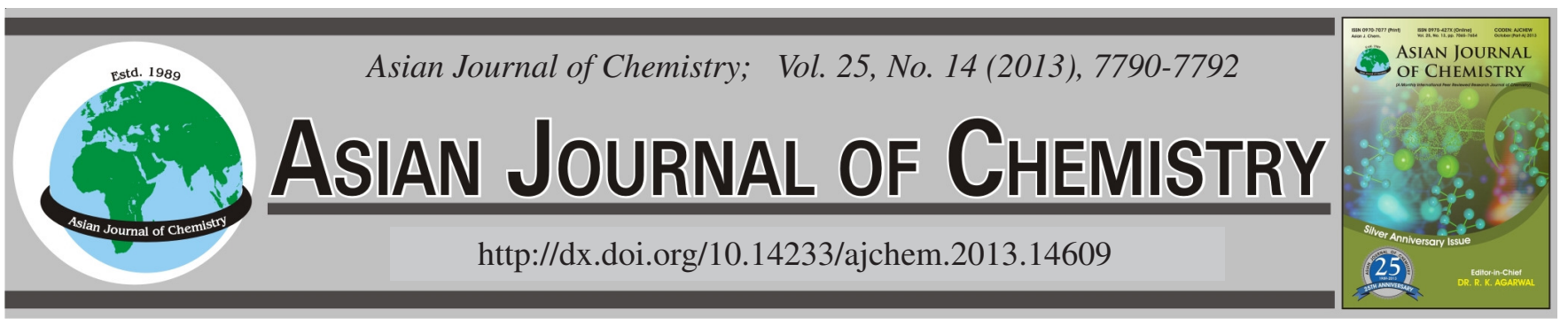

\title{
Antioxidant Activity of Taxillus chinensis Parasitizing on Toona sinensis (A. Juss) Roem
}

\author{
Yanfang Liao ${ }^{1,2}$, Lini Huo ${ }^{1, *}$, Rui CheN ${ }^{3}$, Peiyuan Li ${ }^{1}$ and Rumei Lu ${ }^{1}$
}

${ }^{1}$ College of Pharmacy, Guangxi University of Chinese Medicine, Nanning 530001, P.R. China

${ }^{2}$ Guangxi Research Institute of Chemical Industry, Nanning 530001, P.R. China

${ }^{3}$ College of Chinese Medical Science, Guangxi University of Chinese Medicine, Nanning 530001, P.R. China

*Corresponding author: Tel: +86 15994365816; E-mail: huolini@126.com

\begin{abstract}
The present study describes the in vitro antioxidant activity of petroleum ether, ethyl acetate and $n$-butanol extracts of Taxillus chinensis living parasitically on Toona sinensis (A. Juss) Roem. The antioxidant activity of the extracts was assessed by using the following methods: 1,1-diphenyl-2-picrylhydrazyl and 2,2'-azo-bis(3-ethylbenzothiazoline-6-sulfonic acid) diamonium salt both free radical scavenging assays and reducing assays. The antioxidant activities of various extracts of $T$. chinensis from $T$. sinensis seemed to follow the same trend i.e., $n$-butanol extracts $>$ ethyl acetate extracts $>$ petroleum ether extracts. The results showed that these extracts, especially the $n$ butanol extracts, could be considered as natural antioxidants and may be useful for curing diseases arising from oxidative deterioration.
\end{abstract}

Key Words: DPPH, ABTS, Taxillus chinensis, Host.

\section{INTRODUCTION}

Oxidative stress represents a disturbance in the equilibrium status of prooxidant/antioxidant reactions in living organisms. The excess of reactive oxygen species (ROS) can damage cellular lipids, proteins or DNA and oxidative imbalance has been implicated in a number of many diseases, including cancers, atherosclerosis and heart diseases as well as in the ageing process ${ }^{1}$. In foods, reactive oxygen species can cause lipid peroxidation, which leads to the deterioration of the food ${ }^{2}$. Although some synthetic antioxidant compounds, such as butylated hydroxytoluene (BHT) and butylated hydroxyanisole (BHA), are commonly used for increasing the shelf life of foods. These compounds have been reported to have some side effects ${ }^{3}$. Therefore, there is a good prospect in searching antioxidants from natural plants. Phenolics or polyphenols, including flavonoids have received considerable attention because of their physiological functions such as antioxidant, antimutagenic and antitumor activities ${ }^{4}$. Consequently, quantitative and qualitative determination of flavonoids and phenolics compounds with strong antioxidant capacity has been done for many plant extracts.

Parasites are unusal plants, more than 2500 species of higher plants are known to live parasitically on other plants. Taxillus chinensis belongs to the Loranthaceae family, distributed in Guangdong, Guangxi, Taiwan and Fujian province in china. Some common host trees of T. chinensis are mulberry, plum trees, longan trees, lychee trees and oleander trees, etc.
The pharmacological activities of $T$. chinensis are widely proved in antioxidant, anticancer, antibacterial and fatty acid synthase inhibitory effect ${ }^{5-8}$. Besides, it has been proved that the chemical constituents and biological activities of parasites plants depend to a large extent on the host plant ${ }^{9,10}$. The leaves of Toona sinensis (A. Juss) Roem were proved to possess good antioxidant activity ${ }^{11,12}$. Therefore, the $T$. chinensis living parasitically on this host trees might be a good source of powerful antioxidant. To our best of knowledge, antioxidant activity of T. chinensis parasitizing on $T$. sinensis has not been reported so far. In this report, the extracts of different polarity from them were prepared and studied for their antioxidant activity. 1,1-Diphenyl-2-picryl hydrazyl and 2,2'-Azobis-(3-ethylbenzothiazoline-6-sulfonic acid) assay were carried out to evaluate the antioxidant activity of these extracts.

\section{EXPERIMENTAL}

Taxillus chinensis whole plants parasitizing on Toona sinensis (A. Juss) Roem was obtained from marketplace vendors from Guangxi Province, in August 2010. The voucher specimens were identified by professor Songji Wei at the Department of Zhuang Pharmacy, Guangxi traditional Chinese Medical University. 1,1-Diphenyl-2-picryl hydrazyl (DPPH) (purity $98 \%$ ) was purchased from Wako Chemicals, Japan; 2,2'-azobis-(3-ethylbenzothiazoline-6-sulfonic acid) (ABTS) and butylated hydroxyltoluene (BHT) was purchased from Sigma Aldrich Co., St. Louis, MO, USA; Lutin standard was purchased from J \& K Scientific Ltd., Beijing, China; Other 
chemicals were purchased from China National Medicine Group Shanghai Corporation, Shanghai, China. All chemicals and solvents used were of analytical grade.

Preparation of extracts: The samples were initially air-dried and then reduced to small particles. The particles selected for analysis were passed through a 40-mesh screen and suspended in $95 \%$ ethanol and the filtrate was collected for three times at every $48 \mathrm{~h}$ interval of a $144 \mathrm{~h}$ total collection period. The extracts were concentrated, suspended in deionized water and sequentially partitioned with petroleum ether, ethyl acetate and $n$-butanol to obtain three different fractions (water part was discarded). The petroleum ether extract (XPE), ethyl acetate extract (XEAE) and $n$-butanol extract (XBE) were obtained by concentrating the extract liquid under reduced pressure at $40{ }^{\circ} \mathrm{C}$ using vacuum rotary evaporator and the dry extracts were stored at $-4{ }^{\circ} \mathrm{C}$ until use.

Scavenging activity on DPPH radical: The scavenging effect of different fractions on the DPPH radical was measured using a modified version of the method described by Shimada et al..$^{13}$. In brief, extracts solution $(100 \mu \mathrm{L})$ in $95 \%$ ethanol at different concentration $\left(0.2-2.0 \mathrm{mg} \mathrm{mL}^{-1}\right)$ was added to $4 \mathrm{~mL}$ $0.004 \%(\mathrm{w} / \mathrm{v})$ solution of DPPH in $95 \%$ ethanol. The reaction mixtures were incubated at $28{ }^{\circ} \mathrm{C}$. The scavenging activities on DPPH radical were determined by measuring the absorbance at $515 \mathrm{~nm}$ after $10 \mathrm{~min}$. The antioxidant activity was expressed as a percentage of scavenging of DPPH: SC \% $=[1-($ absorbance of sample)/(absorbance of control) $] \times 100 \%$. The control contains all reagents except the extract. The DPPH radical scavenging activity of BHT at the same concentrate were also assayed for comparison. All tests were performed in triplicate and mean were centred.

$\mathrm{ABTS}^{+\bullet}$ radical cation scavenging: The antioxidant activities of various solvent extracts in the reaction with the stable $\mathrm{ABTS}^{+\bullet}$ radical cation were determined according to the method of Re et al. ${ }^{14}$ with slight modification. The reaction between ABTS and potassium persulfate directly generates the blue/green $\mathrm{ABTS}^{+\bullet}$ chromophore, which can be reduced by an antioxidant, thereby resulting in a loss of absorbance at $734 \mathrm{~nm}$. ABTS was dissolved in water to a $7 \mathrm{mM}$ concentration. ABTS radical cation $\left(\mathrm{ABTS}^{+\bullet}\right)$ was produced by reacting ABTS stock solution with $2.45 \mathrm{mM}$ potassium persulfate (final concentration) and allowing the mixture to stand in the dark at room temperature for $12-16 \mathrm{~h}$. The $\mathrm{ABTS}^{+\bullet}$ solution (stable for 2 days) was diluted with phosphate buffer ( $2 \mathrm{mM}, \mathrm{pH} 7.4)$ to achieve an absorbance of $0.7 \pm 0.05$ at $734 \mathrm{~nm}$. Extracts solution $(20 \mu \mathrm{L})$ in $95 \%$ ethanol at different concentration $(0.5$ $\left.2.0 \mathrm{mg} \mathrm{mL}^{-1}\right)$ were mixed with $\mathrm{ABTS}^{+\bullet}$ solution $(1.9 \mathrm{~mL})$ and then absorbance was read at ambient temperature after 3 min. PBS solution was used as a control. All tests were triplicated. The radical-scavenging activity of the samples was expressed as $\mathrm{SC} \%=\left[\left(\mathrm{A}_{\text {control }}-\mathrm{A}_{\text {test }}\right) / \mathrm{A}_{\text {control }}\right] \times 100 \%$, in which $\mathrm{A}_{\text {control }}$ is the absorbance of the control $\left(\mathrm{ABTS}^{+\bullet}\right.$ solution without test sample) and $\mathrm{A}_{\text {test }}$ is the absorbance of the test sample (ABTS ${ }^{+\bullet}$ solution plus extract).

\section{RESULTS AND DISCUSSION}

DPPH radical scavenging activity: The DPPH free radical is a stable free radical, which has been widely accepted as a tool for estimating free radical-scavenging activities of antioxidants ${ }^{15}$. All extracts were found to be effective scavengers against DPPH radical and scavenging abilities increased steadily with concentration (Fig. 1). XBE possessed a highest scavenging capacity of $85.93 \%$ at $2.0 \mathrm{mg} \mathrm{mL}^{-1}$ on DPPH radical and XBE, XEAE were all superior to the positive control, BHT. By comparing the $\mathrm{IC}_{50}$ (the half maximal inhibitory concentration) value of those active fractions, the free radical scavenging activities followed the order: $\mathrm{XBE}\left(\mathrm{IC}_{50}\right.$ : $0.31 \pm 0.016$ $\left.\mathrm{mg} \mathrm{mL}{ }^{-1}\right)>\operatorname{XEAE}\left(\mathrm{IC}_{50}: 0.58 \pm 0.022 \mathrm{mg} \mathrm{mL}^{-1}\right)>\mathrm{BHT}\left(\mathrm{IC}_{50}\right.$ : $\left.1.52 \pm 0.035 \mathrm{mg} \mathrm{mL}^{-1}\right)>\operatorname{XPE}\left(\mathrm{IC}_{50}: 20.21 \pm 0.147 \mathrm{mg} \mathrm{mL}^{-1}\right)$.

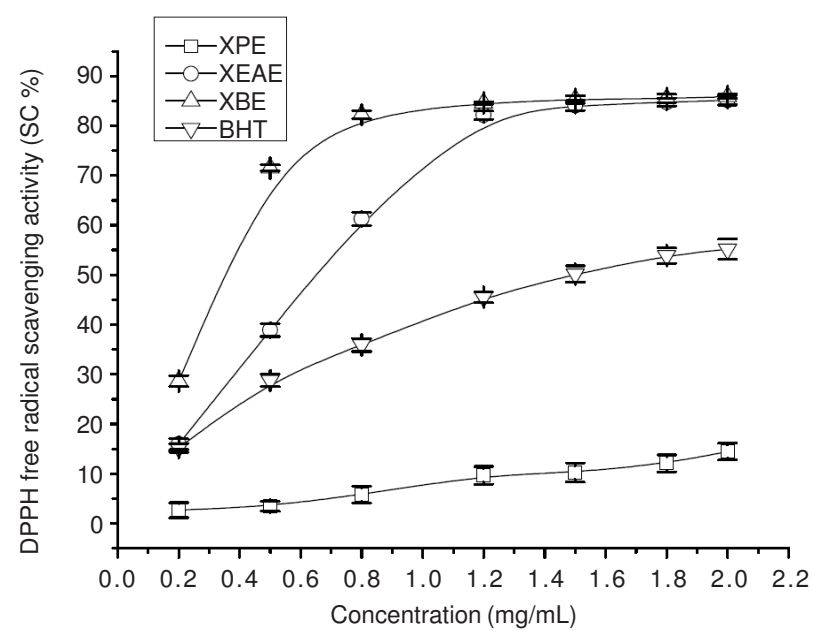

Fig. 1. DPPH radical scavenging activity of all extracts. (Results are mean \pm SD of three parallel measurements. Values are significantly different $(p<0.05)$, when compared to the control, BHT)

$\mathrm{ABTS}^{+}$radical scavenging activity: The scavenging capacities of various extracts on $\mathrm{ABTS}^{+}$radical were measured and compared (Fig. 2). And all extracts and BHT exhibited concentration-dependent ABTS+oscavenging activity. XBE aslo possessed the highest scavenging capacity on ABTS radical $(97.38 \%)$ at $2.0 \mathrm{mg} \mathrm{mL}^{-1}$, which was a little higher than XEAE $(96.42 \%)$. Under the same experimental conditions, the $\mathrm{SC} \%$ of XBE (0.5-2.0 $\left.\mathrm{mg} \mathrm{mL}^{-1}\right)$ and XEAE (0.5-2.0 mg $\mathrm{mL}^{-1}$ ) was higher than BHT at the concentration of $0.2 \mathrm{mg}$ $\mathrm{mL}^{-1}$, but all extracts possessed lower capability of antioxidation than BHT $\left(0.5-2.0 \mathrm{mg} \mathrm{mL}^{-1}\right)$. The ABTS radical scavenging activity of all fractions exhibited the descending order of: XBE $\left(\mathrm{IC}_{50}\right.$ : $\left.0.61 \pm 0.027 \mathrm{mg} \mathrm{mL}^{-1}\right)>\operatorname{XEAE}\left(\mathrm{IC}_{50}\right.$ : $\left.0.66 \pm 0.031 \mathrm{mg} \mathrm{mL}^{-1}\right)>\operatorname{XPE}\left(\mathrm{IC}_{50}: 70.55 \pm 3.48 \mathrm{mg} \mathrm{mL}^{-1}\right)$.

\section{Conclusion}

All the methods employed in this work demonstrated significant antioxidant properties for extracts of T. chinensis living parasitically on $T$. sinensis. XBE proved to be the most efficient extract. The antioxidant properties of all extracts exhibited the descending order of $\mathrm{XBE}>\mathrm{XEAE}>\mathrm{XPE}$, indicating that there is a correspondence between them. This study is the first report on the study of antioxidant activities of T. chinensis from $T$. sinensis and $n$-butanol extract could be considered as potential natural antioxidant sources for medicinal and food applications. Since this investigation is a preliminary study, on the antioxidant mechanisms of specific flavonoids and phenolics components of $T$. chinensis on this 


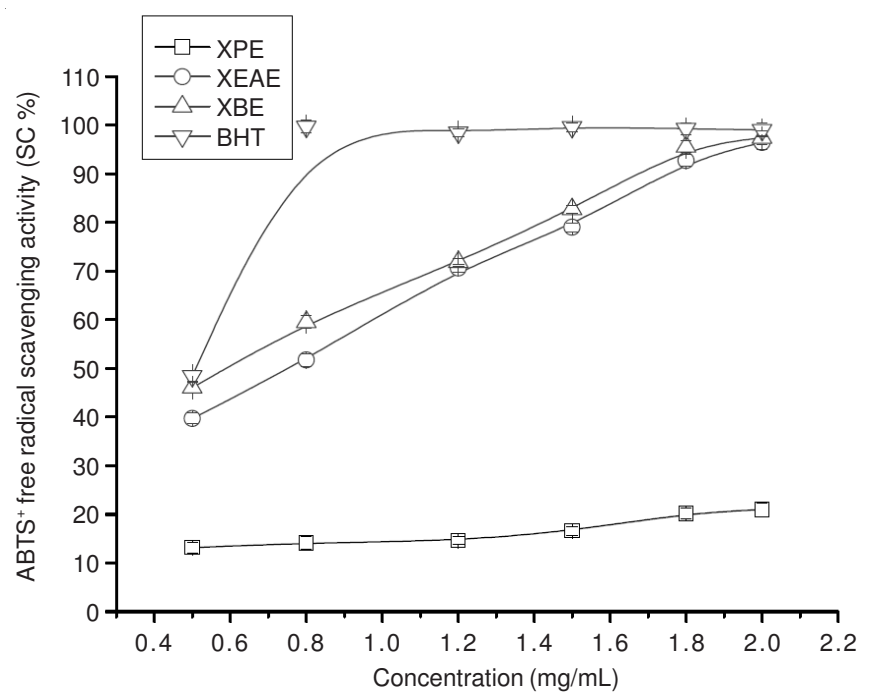

Fig. 2. $\mathrm{ABTS}^{+}$radical scavenging activity of all extracts. Results are mean $\pm \mathrm{SD}$ of three parallel measurements. Values are significantly different $(p<0.05)$, when compared to the control, BHT

plant and the connection between parasites and hosts is absolutely necessary and is in progress.

\section{ACKNOWLEDGEMENTS}

The authors thank the Guangxi Administration of Traditional Chinese Medicine (Grant No. gzzc1208), Guangxi Natural Science Foundation (Grant No. 1013199) for financial support.

\section{REFERENCES}

1. B. Halliwell, The Lancet, 344, 721 (1994)

2. $\quad$ N.J. Miller and C.A. Rice-Evans, Food Chem., 60, 331 (1997).

3. J.P. Kehrer and J. DiGiovanni, Toxicol. Lett., 52, 55 (1990).

4. A. Othman, A. Ismail, A.N. Ghani and I. Adenan, Food Chem., 100, 1523 (2007).

5. P.G. Xiao, S.T. Xing and L.W. Wang, J. Ethnopharmacol., 38, 167 (1993)

6. Y.L. Hua, H.P. Wu and R.R. Zhang, Chin. J. Trad. Chin. Med. Pharm., 10, 40 (1995).

7. J. Sun, B.R. Liu, W.J. Hu, L.X. Yu and X.P. Qian, Phytochem. Res., 21, 1102 (2007).

8. Y. Wang, M. Deng, S.Y. Zhang, Z.K. Zhou and W.X. Tian, J. Ethnopharmacol., 118, 473 (2008).

9. Y.J. Xiao, Y.Z. Chen and B.H. Chen, Chin. J. Chin. Mater. Med., 33, 427 (2008).

10. Y.H. Li, S.L. Chen, D. Lu, K.X. Zhu, M.H. Zhao, H.H. Pei and J.L. Ruan, Lishizhen Med. Mater. Med. Res., 20, 3009.

11. S.J. Li and Y.J. Hu, J. Anhui. Agric. Sci., 35, 6807 (2007).

12. K.N. Prasad, J. Hao, C. Yi, D.D. Zhang, S.X. Qiu, Y.M. Jiang, M.W. Zhang and F. Chen, J. Biomed. Biotechnol., 2009, Article ID 612805 (2009).

13. K. Shimada, K. Fujikawa, K. Yahara and T. Nakamura, J. Agric. Food. Chem., 40, 945 (1992).

14. R. Re, N. Pellegrini, A. Proteggente, A. Pannala, M. Yang and C. Rice Evans, Free Radic. Biol. Med., 26, 1231 (1999).

15. H. Fenglin, L. Ruili, H. Bao and M. Liang, Fitoterapia, 75, 14 (2004). 